\title{
CORRESPONDENCE
}

\section{A NEW OPERATIVE PROCEDURE FOR GLAUCOMA}

To the Editors of THE BRITISH JOURNAL OF OPHTHALMOLOGY.

DEAR SIRS,-Since May of this year, I have been experimenting with a novel operation for glaucoma, to which I gave the name of "cyclanaemisation." I have had already some encouraging results, but neither the technicalities of the operation, nor the experiences are ripe for publication.

In consequence of hindering circumstances it is only now that I could obtain the latest numbers of the Arch. of Ophthal. There I read in an article of Roetth (p. 21), that Guerry invented an antiglaucomatous operation called angiodiathermy in 1944, based on the same principle on which my proceeding was worked out, namely on the coagulative obstruction of the long posterior ciliary arteries.

Nevertheless there is a not unimportant difference between his and my operation. As far as I can infer from the short remarks of Roetth, Guerry coagulates one of the named arteries just anterior to its entrance into the sclera. He seems to have got convincing experimental evidence, that atrophy of the eyeball follows simultaneous coagulation of both vessels.

Contrarily to his proceeding I am obstructing the long ciliary arteries behind the insertions of the horizontal recti, partly by pergamentisation, partly by perforating cauterisation. The muscle is exposed on a squint-hook and drawn to the side by a glass retractor, thus the scleral operating field is made well accessible. The operation performed an both sides of the same eye I have seen only mild atrophy of the iris with pigment-mobilisation. Very expressed and durable hypotony ensued sometimes. Serious damage of the eye has up to now never been observed.

It is probable, that Guerry or somebody else, in prosecuting the mentioned basic principle will find out earlier or later this right and simple way of anaemising the ciliary body: Therefore I beg you to publish these lines as a short preliminary note.

Yours truly,

A. Kettesy, Professor.

UNIVERSITY EYE CLINIC, DEBRECEN, HUNGARY. 